\title{
Therapeutic Approach out of IVF of Ovulation Disorders in Sub-Saharian African
}

\author{
Fanny Mohamed", Dia Jean-Marc ${ }^{2}$, Adjoussou Stephane', Fomba Minata1, Aka Edele1, \\ Koffi Abdoul'1, Konan Jean Marie1, Olou Luc'1, Guie Privat ${ }^{2}$, Kone Mamourou' \\ ${ }^{1}$ Gynecology Department of the University and Hospital Center of Yopougon (CHUY), Abidjan, Côte d'Ivoire \\ ${ }^{2}$ Gynecology Department of the University and Hospital Center of Treichville (CHUT), Abidjan, Côte d'Ivoire \\ Email:*jmlaminedia@yahoo.fr
}

How to cite this paper: Mohamed, F., Jean-Marc, D., Stephane, A., Minata, F., Edele, A., Abdoul, K., Marie, K.J., Luc, O., Privat, G. and Mamourou, K. (2017) Therapeutic Approach out of IVF of Ovulation Disorders in Sub-Saharian African. Open Journal of Obstetrics and Gynecology, 7, 1116-1123. https://doi.org/10.4236/ojog.2017.711112

Received: August 21, 2017

Accepted: October 17, 2017

Published: October 20, 2017

Copyright $\odot 2017$ by authors and Scientific Research Publishing Inc. This work is licensed under the Creative Commons Attribution International License (CC BY 4.0).

http://creativecommons.org/licenses/by/4.0/

\begin{abstract}
Objectives: To describe our management strategy of ovulation disorders. Patients and methods: From a retrospective collection of data from the records, we identified over a period of one year (January 2016-December 2016), 47 patients followed in gynecology department of University and Hospital Centers of Yopougon and Treichville in Abidjan (Côte d'Ivoire) for ovulation disorders. The diagnosis of dysovulation was made following a hormonal check up and a follicular monitoring ultrasound. These patients underwent a specific treatment according to the type of dysovulation they presented. Results: The average age was 31.9 years with a significant proportion of nulliparous (66\%). Body mass index was high in $44.7 \%$ of patients, of whom $19.1 \%$ were obese and $25.6 \%$ overweight. The hormonal balance was disrupted in $48.9 \%$ of cases. Polycystic ovary syndrome (WHO type IIb dysovulation) was the most common pathology (36\%). The proposed treatments were dominated by clomiphene citrate (31.9\%) and gonadotrophins (25.5\%). 14.9\% of pregnancies were obtained. Conclusion: This study allows us to offer better management of ovulation disorders, but this necessarily entails a careful exploration and an appropriate treatment.
\end{abstract}

\section{Keywords}

Infertility, Dysovulation, Ovulation Inducers

\section{Introduction}

Ovulation disorders account for $30 \%-35 \%$ of female infertility [1]. This is a common situation that the gynecologist is confronted with during infertility consultations. The management is subtle and must be based on the clinical context and the hormonal profile of the patient. The therapeutic approach must 
be rigorous. The present study reports our experience in the treatment of dyssovulations with as general objective to contribute to better management of infertile couples in African context. And the specific objectives of this work are: to describe the epidemiological characteristics of patients with dyssovulation; to reveal the hormonal profile of these patients; to indicate our therapeutic management of the dysovulations by specifying our results in terms of pregnancy obtained.

\subsection{Patients and Methods}

This was a retrospective and cohort study with descriptive purpose conducted from $1^{\text {st }}$ January 2016 to $31^{\text {st }}$ December 2016 (12 months period), in the gynecology department of University and Hospital Centers of Yopougon (CHUY) and Treichville (CHUT) in Abidjan (Côte d'Ivoire). The study involved women who came to consult for infertility and whose spouses had a normal spermogram. We included patients who had an endovaginal ultrasound which evoked the diagnosis of dysovulation and who achieved the hormonal balance required, and followed the treatment indicated for this purpose. We excluded patients with uterine and tubal abnormalities, and those who had incomplete files. Thus, our study concerned 47 patients.

\subsection{Minimal Exploration of Patients Consulting for Infertility in Our Services}

Women who consult in our services for infertility must achieve a minimal check up including an endovaginal ultrasound exploration, a hormonal balance, hysterosalpingography, and a spermogram at their spouses.

- Endovaginal ultrasound exploration: The ultrasound exploration of the ovulation required an endovaginal ultrasound for follicular monitoring: this monitoring of ovulation necessitated peri-ovulatory ultrasounds on the 8th, 12 th and 16th day of the cycle, aiming at objectifying the dominant follicle and then monitoring its growth until eventual ovulation.

- The hormonal balance: It was carried out on the third day of the cycle and consisted of a blood dosage of the following hormones: FSH, LH, Estradiol, Prolactin. We considered as cut-off acccording to Merviel [2], the following values: FSH: $12 \mathrm{mI} / \mathrm{ml}$; LH: $8 \mathrm{mIU} / \mathrm{ml}$; Oestradiol: $70 \mathrm{pg} / \mathrm{ml}$; Prolactin: 25 $\mathrm{ng} / \mathrm{ml}$.

\subsection{Collection and Dataexploitation}

The data were collected after the examination of the files of the patients covering the period of study on a fact sheet prepared for this purpose. The analysis of the data entered was carried out with the software EPI-INFO 6.04.

\section{Results}

\subsection{Epidemio-Clinical Characteristics}

The CHUY and CHUT are level 3 center of the heath pyramid in Côte d'Ivoire. 
And during the study period, we received 1135 couples for infertitlity including 623 in CHUy and 512 in CHUT. Among this couples, 47 women met our inclusion criteria.

The average age of our patients was 31.9 years with the extremes at 18 years and 43 years. A peak frequency was observed between 30 and 34 years (57.4\%), and $38.3 \%$ of our patients were between 35 and 45 years old. $2 / 3$ of our patients (66\%) were nulliparous, and $70.2 \%$ had a duration of infertility between 2 and 4 years. Almost half of our patients (46.8\%) had an irregular cycle while $53.2 \%$ of our patients had a cycle time of 28 to 31 days. The average body mass index (BMI) of our patients was 25.33. Among these patients, 55.3\% had normal weight, $25.6 \%$ were overweight and $19.1 \%$ were obese.

\subsection{Hormonal Profile}

Twenty-three patients (48.9\%) had a hormonal upset: FSH $>12 \mathrm{mIU} / \mathrm{ml}$ in 5 patients; $\mathrm{LH}>8 \mathrm{mIU} / \mathrm{ml}$ in 7 patients; Isolated hyperoestrogenism $>70 \mathrm{mIU}$ in 3 patients; Hyperoestrogenism associated with high FSH in 3 patients; Hyperprolactinemia in 5 patients.

\subsection{Type of Observed Dysovulation}

A typical echographic appearance of PCOS was found in $36.2 \%$ of our patients. In $31.9 \%$ of patients, slow follicular growth was observed . A follicular cystitis was encountered in $21.3 \%$ of cases (Table 1 ).

\subsection{Treatment}

Clomiphene citrate and gonadotrophins were the most commonly used ovulation inducers. They accounted for $2 / 3(68 \%)$ of the proposed treatments (Table 2).

\subsection{Pregnancy Occurrence}

Seven patients (14.9\% of our study population) had a pregnancy. It was a single pregnancy.

All our pregnant patients (7) had a normal initial hormonal balance.

Table 1. Distribution of patients according to the type of observed dysovulation.

\begin{tabular}{|c|c|c|c|}
\hline & TYPE OF DYSOVULATION & POPULATION & PERCENTAGE (\%) \\
\hline- & Follicular cyst & 10 & 21.3 \\
\hline- & PCOS (type II b) & 17 & 36.2 \\
\hline- & Poor follicular ovary (type III) & 5 & 10.6 \\
\hline- & Follicular growth retardation & 15 & 31.9 \\
\hline & Total & 47 & 100 \\
\hline
\end{tabular}

PCOS: polycystic ovary syndrome. 
Table 2. Distribution of patients according to the type of treatment received.

\begin{tabular}{lcc}
\hline \multicolumn{1}{c}{ TREATMENT RECEIVED } & POPULATION & PERCENTAGE (\%) \\
\hline - Diet & 4 & 8.5 \\
- Clomifene Citrate & 15 & 31.9 \\
- $\quad$ HMG or FSH (Gonadotrophins) & 12 & 25.5 \\
- Clomifene citrate + Diet & 4 & 8.5 \\
- Clomifene citrate + HMG or FSH & 5 & 10.6 \\
- Clomifene citrate + cabergoline & 2 & 4.3 \\
$-\quad$ HMG or FSH + Diet & 2 & 4.3 \\
- Diet + Cabergoline + Metformin & 3 & 6.4 \\
TOTAL & 47 & 100 \\
\hline
\end{tabular}

\subsection{Number of Cycles of Treatment before Pregnancy Occurrence}

$57.2 \%$ of the pregnancies (4 patients) occurred after 3 cycles of treatment (Table 3).

\subsection{Type of Treatment Received and Pregnancy Occurrence}

Drug treatments were undertaken in 6 patients $(85.7 \%)$ before they got pregnant (Table 4).

\section{Discussion}

This study has some limitations linked to the weakness of the sample because all the patients could not afford the cost of management. Thus many patients having not been able to perform the explorations or treatments needed were excluded from the study.

\subsection{Epidemio-Clinical Characteristics}

In our study, the average age was 31.9 years with the extremes at 18 years and 43 years.

Patients aged between 30 and 34 accounted for more than half of our population (57.4\%). Our finding is identical to that of SCHWART [3] who reports that the average age of infertility is 32 years in his series.

The rate of conception per cycle varies according to age: it is $24 \%$ at 25 years, $12 \%$ at 35 years and $6 \%$ at 40 years [4]. The decrease in female fertility with age is now demonstrated mainly from Of 35 years [5]. Yet we see that women have their first born child at a late age.The majority of our patient were more than 30 years old and were nulliparous (66\%). In 1991, on FIV NAT [6], it was already reported that $70 \%$ of infertile women were nulliparous. For BELAISH-ALLART [5], this could be explained by a better control of contraception, current difficulties in professional life without counting unstable unions. 
Table 3. Distribution according to the number of cycles of treatment before pregnancy occurrence.

\begin{tabular}{ccc}
\hline NUMBER OF CYCLES & POPULATION & PERCENTAGE (\%) \\
\hline 1 & 2 & 28.6 \\
2 & 1 & 14.3 \\
3 & 1 & 14.3 \\
7 & 1 & 14.3 \\
12 & 2 & 28.6 \\
TOTAL & 7 & 100 \\
\hline
\end{tabular}

Table 4. Distribution according to the type of treatment received before pregnancy occurrence.

\begin{tabular}{|c|c|c|c|}
\hline & TYPE OF TREATMENT RECEIVED & POPULATION & PERCENTAGE (\%) \\
\hline- & Clomifene Citrate & 2 & 28.6 \\
\hline & FSH or HMG & 3 & 42.8 \\
\hline- & Clomiphene citrate + Diet & 1 & 14.3 \\
\hline- & Diet & 1 & 14.3 \\
\hline & TOTAL & 7 & 100 \\
\hline
\end{tabular}

In addition to age, being overweight can be a factor in ovulation disorders. According to OLIVENNES, weight is the first factor to consider: a weight too low ( $<45 \mathrm{kgs})$ or an obesity ( $>85 \mathrm{kgs})$ are responsible for ovulation disorders [7]. In our series we observed that $25.5 \%$ of our patients were overweight and $19.2 \%$ were obese. Authors like DICKEY [8] think that weight correction is essential and can alone restore ovulation.

In our study population, $46.8 \%$ of patients had an irregular cycle. LANSAC [9] describes irregular cycles with ovulation disorders in women around perimenopause, which begins at about 40 years of age and sometimes from 35 years. Our results seem to confirm the author's observation because $38.3 \%$ of our patients were between 35 and 45 years old.

The duration of infertility would have a pejorative role on procreation: the older the infertility, the lower the chance of getting pregnant [10]. Thirty-three patients (70.2\% of our population), had a duration of infertility between 2 and 4 years. SCHWARTZ also made the same observation by reporting in his series, a duration of infertility of 3 years in $89 \%$ of cases and of 2 years in $52 \%$ [4].

The age of the patient and the duration of infertility are therefore two essential parameters to be taken into account.

\subsection{Hormonal Profile}

Several patients in our series (48.9\%) had a disturbedhormonal balance. The studies carried out by FRYDMAN [11] gave the following results: in an ovarian 
stimulation, among women with an ovarian reserve judged "normal" 6\% were interrupted compared to $37 \%$ of women with ovarian reserve "altered". He states at the same time that the average level of plasma FSH is also significantly higher in women whose treatment has been interrupted for bad response. Its results demonstrate the influence of the ovarian reserve on ovarian stimulation and therefore on the quality of follicular growth.

\subsection{Type of Diagnosed Dysovulation}

In our study population, PCOS were the most important echographic aspects of dysovulation (6.2\%). Our finding is similar to that of TEISSIER [12], who thus considers that PCOS represent the most common etiology of infertilities affecting $5 \%$ to $10 \%$ of infertile women [12].

\subsection{Treatment}

The treatments used were essentially clomiphene citrate, gonadotropins and diet,accounting for $57.4 \%$ of all treatments. Like us Dickey reported a series where he resortedto clomiphene citrate in first-line and to gonadotrophins in second-line [8]. He also recommended for overweight patientsto reduce their weight to drop thehyperinsulinism and facilitate the induction of ovulation. It is in this perspective of reduction of hyperinsulinism that we have resorted to Metformin. And the cabergoline has been useful in hyperprolactinemia.

\subsection{Treatment Outcomes}

$14.9 \%$ of our patients got pregnant after treatment. DICKEY, meanwhile, reported pregnancy rates of $20 \%-40 \%$ with clomiphene citrate and $12 \%-24 \%$ with gonadotrophins [8]. HAZOUT obtained pregnancy rates of 18 to $30 \%$ [13]. Differences in outcome could be related to sampling.

\subsection{Number of Cycles of Treatment before Pregnancy Occurrence}

In our study, 4 out of 7 patients were able to obtain a pregnancy after 3 cycles of treatment.

Our results are consistent with those of DICKEY [8] who report that the majority of pregnancies occur in the first six cycles of treatment.

Therefore it is reasonable, beyond six cycles of stimulation well conducted to consider to resortto medically assisted procreation (MAP) rather than to relentless pursuit of stimulation.

\subsection{Type of Treatment Received and Pregnancy Occurrence}

The purpose of the treatment being to achieve a progressive pregnancy, it is therefore essential to evaluate all the factors of infertility of the couple. The therapeutic strategy should take into account the age of the woman, the duration of infertility, the weight and the type of dysovulation according to the WHO classification. 
Thus according to the ageit is not recommanded to use an ovulation induction therapy after 45 years, regardless of the FSH base rate, because the term pregnancy rates are extremely low and fetal and maternal risks are maximum. Concerning the weight, it isadvised that it should be closer to the normal one through hygiene and dietary measures before any ovulation stimulation.

Talking about the dysovulation, WHO gives indications according to their types. The Type I dysovulation called central dysovulation, must be treated by the GnRH pump. The Type IIa or idiopathic dysovulation, must be treated in first intention using clomiphene citrate and gonadotropins in second intention in case of failure to clomiphene citrate after 6 cycles. For the Type IIb or PCOS, first start with the dietary care eventually associated with clomiphene citrate and then in case of failure after 6 cycles of clomiphene citrate, use gonadotropins.An adjuvant therapy with Metformin could also be added.

In the Type III, theuse of the ovulation induction is useless and the couple must be oriented to the MAP with a gametes donationor adoption.

Moreover, in case of hyperprolactinemia, a hypoprolactinaemic must be associated.

\section{Conclusion}

This study allowed us to determine the epidemio-clinical factors influencing ovulation in our population. Hormonology showed that the PCOS has been the most common pathology in ovulation disorders. The use of ovulation inductions permitted to correct some abnormalities and obtain pregnancies. However, in order to avoid abusive and blind use of ovulation inductions, prior careful exploration is fundamental.

\section{References}

[1] Thonneau, P. and Spira, A. (1991) Incidence and Main Causes of Infertility in a Resident Population of Three French Regions 1988-1989. Human Reproduction, 6, 811-816. https://doi.org/10.1093/oxfordjournals.humrep.a137433

[2] Merviel, P., Lourdel, E., Cabry, R., Brzakowski, M., Boulard, V., Brasseur, F., et al. (2011) Bilanactualisé de l'Infertilitéen 2011. 16 èmesJournées des Techniques Avancées en gynécologie-obstétrique, infertilité Sage-Femme néonatologie et pédiatrie, Guadeloupe.

[3] Schwartz, D. (1996) L'approche épidémiologique en fertilité humaine. In: SFEF Recherches récentes sur l'épidémiologie de l'infertilité, Masson, Paris.

[4] Schwartz, D. (1981) Importance of the Duration of Infertility in the Assessment of Couple Fecundity. Population, 237-250.

[5] Belaisch-Allart, J. (2006) Quels sont l'apport diagnostique démontré et les effets négatifs éventuels des méthodes d'exploration, les facteursféminins: l'ovulation. Gynecol Obstet Fertil, 34, 881-882.

[6] FIV-NAT. (1991) Age des femmes et fécondation in vitro. Contracept Fertil Sex, 19, 2192-2198.

[7] Olivennes, F., Hazout, A. and Frydman, R. (2006) Exploration du couple infertile in Assistance Médicale à la procréation. 3th Edition, Masson, Paris, 13-48. 
[8] Dickey, R.P., Olar, T.T., Taylor, S.N., Curole, D.N. and Rye, P.H. (1993) Sequential Clomiphene Citrate and Human Menopausal Gonadotrophin for Ovulation Induction: Comparisons to Clomiphene Citrate Alone and Human Menopausal Gonadotrophin Alone. Human Reproduction, 8, 56-59.

https://doi.org/10.1093/oxfordjournals.humrep.a137874

[9] Lansac, J. (1985) Physiologie de la ménopause. Contracept Fertil Sex, 13, 271-276.

[10] Schwartz, D. (1983) Mesure de la fertilité des couples: contribution des deux partenaires. Contracept Fertil Sex, 11, 897-900.

[11] Frydman, R. (2005) Bilan des annulations à l'hôpital Antoine-Béclère entre Novembre 2004 et Mars 2005. Masson, Paris, 10-13.

[12] Teisser, M., Combs, C. and Lopez, S. (2004) Le syndrome des ovaries polykystiques: Quels elements diagnostiques retenir en 2004? Métabolisme Hormones Diabète et Nutrition (VIII), 159-163.

[13] Hazout, A., De Ziegler, D., Cornel, C., Fernandez, H., Lelaidier, C. and Frydman, R. (1993) Comparison of Short 7 Day and Prolonged Treatment with Gonadotrophin Releasing Hormone Agonist Desensitization for Controlled Ovarian Hyperstimulation. Fertility and Sterility, 3, 596-600. https://doi.org/10.1016/S0015-0282(16)55806-3 